\title{
SABERES TRADICIONAIS E CONSERVAÇÃO DA BIODIVERSIDADE: USOS, FAZERES E VIVÊNCIA DOS AGRICULTORES DE UMA COMUNIDADE DE
} ANANINDEUA - PA

\author{
TRADITIONAL KNOWLEDGE AND BIODIVERSITY \\ CONSERVATION: USES, PRACTICES AND EXPERIENCE \\ OF SMALLHOLDERS OF A COMMUNITY IN \\ ANANINDEUA - PA
}

\author{
Neriane Nascimento da Hora \\ Universidade do Estado do Pará - Belém - PA - Brasil \\ Hélio Raymundo Ferreira Filho \\ Universidade do Estado do Pará - Belém - PA - Brasil
}

Ana Cláudia Caldeira Tavares Martins

Universidade do Estado do Pará - Belém - PA - Brasil

Maria de Jesus da Conceição Ferreira Fonseca (In memorian)

Universidade do Estado do Pará - Belém - PA - Brasil

\begin{abstract}
Resumo: $\mathrm{Na}$ atual crise ambiental, busca-se encontrar uma nova forma de relação sociedade-natureza que integre o uso dos recursos naturais à conservação da biodiversidade. Nesse contexto, incluem-se as atividades produtivas de pesca, agricultura, extrativismo, caça, dentre outras. Desse modo, este estudo investiga saberes sobre conservação da biodiversidade presentes na atividade de produção agrícola de moradores da comunidade Igarapé Grande, ilha João Pilatos, AnanindeuaPará. Os dados foram coletados por meio de entrevistas semiestruturadas com nove agricultores; informais, com quatorze indivíduos; e observação participante, com os moradores locais, analisados a partir de análise de conteúdo. Os agricultores de Igarapé Grande desenvolvem, principalmente, sistemas de cultivo baseado nos roçados e nos quintais agroflorestais, nos quais são cultivados, sobretudo Manihot esculenta Crantz, Euterpe oleracea Mart. e Theobroma grandiflorum (Wild. Ex Spreng.) Schum. Eles também sobrevivem de outras atividades, como a pesca, extrativismo vegetal,
\end{abstract}


Neriane N. da Hora, Hélio R. Ferreira. Filho, Ana Cláudia C. T. Martins, Maria J. C. F.

Fonseca

criação de aves, artesanato, e em menor escala, caça e pecuária. A atividade agrícola em Igarapé Grande fundamenta-se em saberes ambientais relacionados à escolha da área para o plantio, à época do plantio/safra, aos procedimentos e técnicas e áreas sem cultivo. Os agricultores reconhecem a importância da conservação da biodiversidade na comunidade Igarapé Grande, e, portanto, desenvolvem técnicas que promovem o enriquecimento das capoeiras, preservam áreas de floresta primária e de mata ciliar e conservam a agrobiodiversidade.

Palavras chaves: Roçados Amazônicos. Quintais Agroflorestais. Agrobiodiversidade.

Abstract: In the current environmental crisis people seek a new form of relationship between society and nature that can integrate the use of natural resources and biodiversity conservation. In this sense are included productive activities such as fishing, agriculture, harvesting and hunting, among others. In this context, this study investigates knowledge of biodiversity conservation present in the agriculture of the inhabitants of Igarapé Grande on João Pilatos Island in Ananindeua - Pará. Data were collected through semi-structured interviews with nine smallholders and a dozen more non-structured interviews with area residents along with participant observation, and were evaluated using content analysis. The smallholders from Igarapé Grande develop, mostly, agriculture systems based on 'roçados' and homegardens for which the main crop is Manihot esculenta Crantz, Euterpe oleracea Mart. e Theobroma grandiflorum (Wild. Ex Spreng.) Schum. Fishing, plant extractivism, poultry creation, handicraft and, in smaller scale, hunting and cattle raising, are other activities performed. Agrarian activity in Igarapé Grande is based on environmental knowledge related to selection of crop sites, time of planting and harvesting, procedures and techniques and areas with no crops. Smallholders recognize the importance of biodiversity conservation in Igarapé Grande, and, thus, developed techniques that promote secondary forest enrichment, primary and riparian forest preservation and agrobiodiversity conservation.

Keywords: Amazon 'roçados'. Homegardens. Agrobiodiversity.

\section{INTRODUÇÃO}

Comunidades tradicionais, povos tradicionais, populações tradicionais ${ }^{1}$ são termos comumente utilizados para designar os grupos sociais culturalmente diferenciados das sociedades urbanos - industriais (HANAZAKI et al., 2010). Nessa categoria, são listados: indígenas²,

\footnotetext{
1 A definição do termo "população tradicional" e suas variantes não é consensual entre os pesquisadores (CUNHA; ALMEIDA, 2000; DIEGUES, 2008). Há uma definição legal dada pelo decreto $\mathrm{n}^{\circ} 6040$ de 07 de fevereiro de 2007 (BRASIL, 2007).

2 Cunha e Almeida (2000) consideram que os povos indígenas, no caso brasileiro, compõe uma categoria diferenciada em relação aos demais povos e comunidades
}

Redes (St. Cruz Sul, Online), v. 20, n² 2, p. 308 - 335, maio/ago. 2015309 
quilombolas, quebradeiras de coco, caiçaras, coletores da mangaba, seringueiros, ribeirinhos, extrativistas, pescadores, dentre outros. Entre algumas de suas características, Pereira e Diegues (2010) destacam o uso e manejo dos recursos naturais e, consequentemente, o desenvolvimento de atividades produtivas (pesca, caça, cultivo agrícola, criação de animais etc.), no qual se estabelece também uma forte ligação com o território.

A dependência direta das comunidades tradicionais com 0 ambiente configura uma modalidade de relação sociedade-natureza diferenciada das sociedades ocidentais (DIEGUES; ARRUDA, 2001; TOLEDO; BARRERA-BASSOLS, 2009). É uma relação considerada de baixo impacto ambiental (CUNHA; ALMEIDA, 2000) e, portanto, que pode propiciar a conservação da diversidade biológica (SHEN et al., 2012; SILVA; FRAXE, 2013). Nesse sentido, frente à crise ambiental, o modo de vida e os saberes dessas populações têm sido arrolados como importantes instrumentos para a conservação ambiental (PEREIRA; DIEGUES, 2010).

Os saberes tradicionais ou saberes ecológicos tradicionais são um conjunto de conhecimentos sobre a vida, o meio ambiente, os seres vivos, o homem etc., bem como a interação entre todos esses elementos expressos por meio de crenças, usos e práticas de um grupo social (TOLEDO; BARRERA-BASSOLS, 2008; REYES-GARCÍA, 2009). Lévi-Strauss (1989) situa os saberes tradicionais como conhecimento baseado no concreto, daí a denominação "ciência do concreto", uma vez que ela também é construída por intermédio de experimentações e observações ao longo de anos, bem como de refutações e validações.

A transmissão dos saberes tradicionais sucede ao longo das gerações a partir da oralidade na vivência dos mais velhos com os mais novos (DIEGUES, 2008). São produzidos, na maioria das vezes, por pessoas iletradas e sem instrução escolar, todavia isso não o invalida como forma de conhecimento, porquanto resultam de observações e experiências de pessoas tão perspicazes quanto aqueles que estão na academia (ELISABETSKY, 2003).

Dentre alguns estudos pioneiros sobre a relação dos saberes tradicionais com a conservação ambiental têm-se: Gadgil; Berkes; Folke (1993) e Balée (1994). Atualmente, este número tem crescido e contemplado vários continentes, como Gómez-Baggetun et al. (2010) na Europa, Shen et al. (2012), Camacho et al. (2012) na Ásia e Ramstad et al. (2007) na Oceania. Tais estudos apontam e reiteram a importância

tradicionais, visto que estes possuem direito à terra, enquanto que os demais povos, exceto quilombolas, ainda lutam por esse direito, e também por conta da língua dos povos indígenas, em geral, ser diferente do idioma oficial do país. 
dos saberes dessas comunidades no que se refere à conservação e utilização sustentável da biodiversidade.

A discussão atual sobre o papel das comunidades na conservação ambiental pauta-se na integração dos conhecimentos tradicionais aos conhecimentos científicos (HANAZAKI et al., 2010; BOHENSKY; MARU, 2011 ) e na inclusão dos habitantes na gestão dos recursos naturais para conservação e utilização sustentável (CHARNLEY et al., 2007; POTTERBOLLAND et al., 2012).

Esse é o caso da parte insular da Região Metropolitana de Belém $(\mathrm{RMB})^{3}$, que é uma área remanescente da floresta original da mesma (AMARAL et al., 2009; FERREIRA et al., 2012), na qual residem comunidades que sobrevivem da pesca, extrativismo vegetal, atividades agrícolas etc. (ALMEIDA; JARDIM, 2012; DINIZ et al., 2012). Este estudo reporta-se à comunidade Igarapé Grande da ilha João Pilatos, pertencente ao Município de Ananindeua, inserido na RMB.

João Pilatos é a maior ilha do Município de Ananindeua e possui uma cobertura vegetal representativa. Entretanto, ela começa a apresentar indícios de antropização, principalmente devido à área de uma fábrica desativada ter sido invadida por moradores de bairros periféricos de Ananindeua no ano de 2005. Esses indivíduos desconhecem os sistemas de uso tradicionais da terra, bem como não apresentam os conhecimentos necessários relacionados ao modo de vida dependente de forma direta dos recursos naturais, como relatado no estudo de Diniz (2010).

Frente à importância das ilhas como remanescentes florestais e do processo de continuidade da perda da cobertura florestal da RMB nos últimos anos (LEÃO et al., 2008), faz-se necessário conhecer a relação das famílias da comunidade Igarapé Grande com o uso da diversidade biológica ${ }^{4}$, entre os quais, relacionados à terra. Portanto, este estudo objetivou analisar a contribuição dos saberes presentes nas atividades agrícolas para a conservação da biodiversidade na comunidade Igarapé Grande, ilha de João Pilatos, Ananindeua-PA.

Dessa forma, a questão norteadora deste trabalho é: quais os saberes sobre conservação da biodiversidade se fazem presentes nas atividades de produção agrícola de moradores da comunidade Igarapé Grande, ilha de João Pilatos, Ananindeua-PA? Assim, poder-se-á indicar caminhos para tornar essa comunidade cogestora dos recursos naturais visando a sua conservação.

\footnotetext{
${ }^{3}$ Concentra os municípios de Belém, Ananindeua, Marituba, Santa Bárbara e Benevides (ANANINDEUA, 2013).

4 Entendida nos seus três níveis de compreensão: variedade de espécies, genes e ecossistemas (PRIMACK; RODRIGUES, 2001).
} 


\section{AGRICULTURA E CONSERVAÇÃO DA BIODIVERSIDADE}

Em substituição ao extrativismo, o cultivo agrícola trouxe inúmeros benefícios à humanidade, entre os quais, ampliação e melhoramento da produtividade e fixação do homem à terra, garantindo, assim, sua sobrevivência e crescimento populacional (PATERNIANI, 2001). Essa prática, no entanto, envolve custos agrícolas e ambientais, uma vez que simplifica o ambiente natural ao ocasionar perda da diversidade biológica, erosão do solo e perturbação de processos ecológicos (MERCADANTE, 2008).

Por outro lado, se a produção agrícola fosse extinta, a humanidade também seria, visto que a obtenção de alimentos a partir da coleta e caça seria insuficiente para alimentar a população mundial (MAZOYER; ROUDART, 2010). Essa assertiva gera o seguinte impasse: como harmonizar a conservação da diversidade biológica com 0 desenvolvimento de atividades produtivas? Questão expressiva no caso brasileiro, detentor de uma megadiversidade biológica e, ao mesmo tempo, com grande potencial para produção de alimentos (MARTINELLI; FILOSO, 2009).

Nesse contexto, a região amazônica é o centro das discussões, haja vista que ela possui a maior floresta tropical contínua do mundo, provê inúmeros serviços ambientais e detém uma biodiversidade inestimável (FEARNSIDE, 2008; MITTERMEIER et al., 2003; RYLANDS et al., 2002). Contudo, o cenário de desenvolvimento aplicado para a região permanece na ampliação das fronteiras agrícolas apoiada na agricultura intensiva, acarretando sérios problemas à manutenção da diversidade biológica dela (VIEIRA et al., 2008; GAZONI; MOTA, 2010). Soma-se a isso o avanço das pastagens, que tem sido o principal fator do desmatamento na região, provocando perda de imensas áreas de floresta e de biodiversidade (FEARNSIDE, 2005; RIVERO et al., 2009).

A implantação de sistemas de uso da terra/sistemas de produção sustentáveis, sobretudo adaptados à agricultura familiar, é uma alternativa para concretização do desenvolvimento sustentável da região, o que inclui a conservação da biodiversidade (HURTIENNE, 2005).

A mão de obra familiar é a base da agricultura tradicional amazônica (NODA et al., 2012). Ela se fundamenta na agricultura itinerante 5 , inicialmente praticada pelos indígenas e que, posteriormente, foi incorporada e redimensionada pelos povos imigrantes - colonizadores europeus e nordestinos (KITAMURA, 1982; FEARNSIDE, 1989). Esse tipo de agricultura foi, por muito tempo, o

\footnotetext{
${ }^{5}$ Também é conhecida como agricultura de corte e queima e agricultura migratória. Em Inglês, podem ser encontradas as palavras slash-and-burn, shifting cultivation ou swidden.
} 
principal modelo de uso e ocupação do solo amazônico (MORAN, 1990), notadamente por meio do sistema de roças, tendo como componente principal a mandioca (MARTINS, 2005).

A agricultura itinerante caracteriza-se pela derrubada, queima, plantio e pousio de uma área de vegetação primária, ou então de uma área em sucessão secundária (capoeira) em diferentes estágios (COOMES et al., 2000; PEREIRA et al., 2006; RICHERS, 2010). Em estudo entre os índios kayapó, Posey (1986) assinala a importância das capoeiras para a manutenção da diversidade biológica amazônica, pois diversas espécies, incluindo florestais, são plantadas nesses "campos abandonados". Assim sendo, atuais florestas consideradas prístinas na Amazônia podem ter sido florestas secundárias no passado, oriundas de antigas capoeiras manejadas pelos indígenas (HECKENBERG et al., 2003; HECKENBERG et al., 2007).

Por outro lado, estudos que reportam mudanças no uso do solo relacionadas à agricultura tradicional, em virtude do crescimento demográfico e pressões econômicas, têm ampliado o debate sobre a real contribuição desta na conservação da biodiversidade (PEDROSO JUNIOR et al., 2008). Frente a isso, defende-se a transformação da agricultura tradicional por meio de técnicas e tecnologias modernas desenvolvidas pela ciência (LEAL et al., 2006; RODRIGUES et al., 2007; LUIZÃO et al., 2009).

Nesse cenário, técnicos e/ou assistentes rurais, na tentativa de transformação da agricultura desenvolvida pelas populações campesinas e etnicamente diferenciadas, buscam promover a difusão de conhecimentos científicos relacionados à atividade agrícola. No entanto, na maioria das vezes, ocorre certo estranhamento entre os técnicos e as comunidades, resultando na rejeição do saber científico, porquanto nessa aproximação, a lógica dos saberes locais e a realidade dos moradores é desconsiderada (SILVA JUNIOR; BIASE, 2012).

Assim sendo, buscar compreender o modo de vida, as formas de manejo e usos da terra dos agricultores de Igarapé Grande entende-se como meio mais eficaz ao diálogo sobre uma gestão compartilhada dos recursos naturais visando à conservação da biodiversidade, bem como a reprodução física e social desses indivíduos.

\section{PROCEDIMENTOS METODOLÓGICOS}

Esta pesquisa caracteriza-se como um estudo de caso (CHIZZOTTI, 2011), de caráter exploratório e, predominantemente, de natureza qualitativa, pois não se detém a interpretação de dados numéricos, mas está voltada para a compreensão do contexto em que os dados estão inseridos (AMOROZO; VIERTLER, 2010). Sendo assim, 
optou-se por aplicação de uma amostragem não probabilística (ALBUQUERQUE et al., 2010b).

Foi realizada na comunidade Igarapé Grande, situada na ilha João Pilatos, Ananindeua-PA (010 16' 22.3" S e 480 22' 50.4" W) (Figura 01). Optou-se por esta área devido à representatividade territorial (3.854,7138 ha6) da mesma; sendo assim, a conservação da diversidade biológica da ilha é significativa para a RMB.

Figura 1. Mapa de Localização da ilha João Pilatos, Ananindeua, Pará

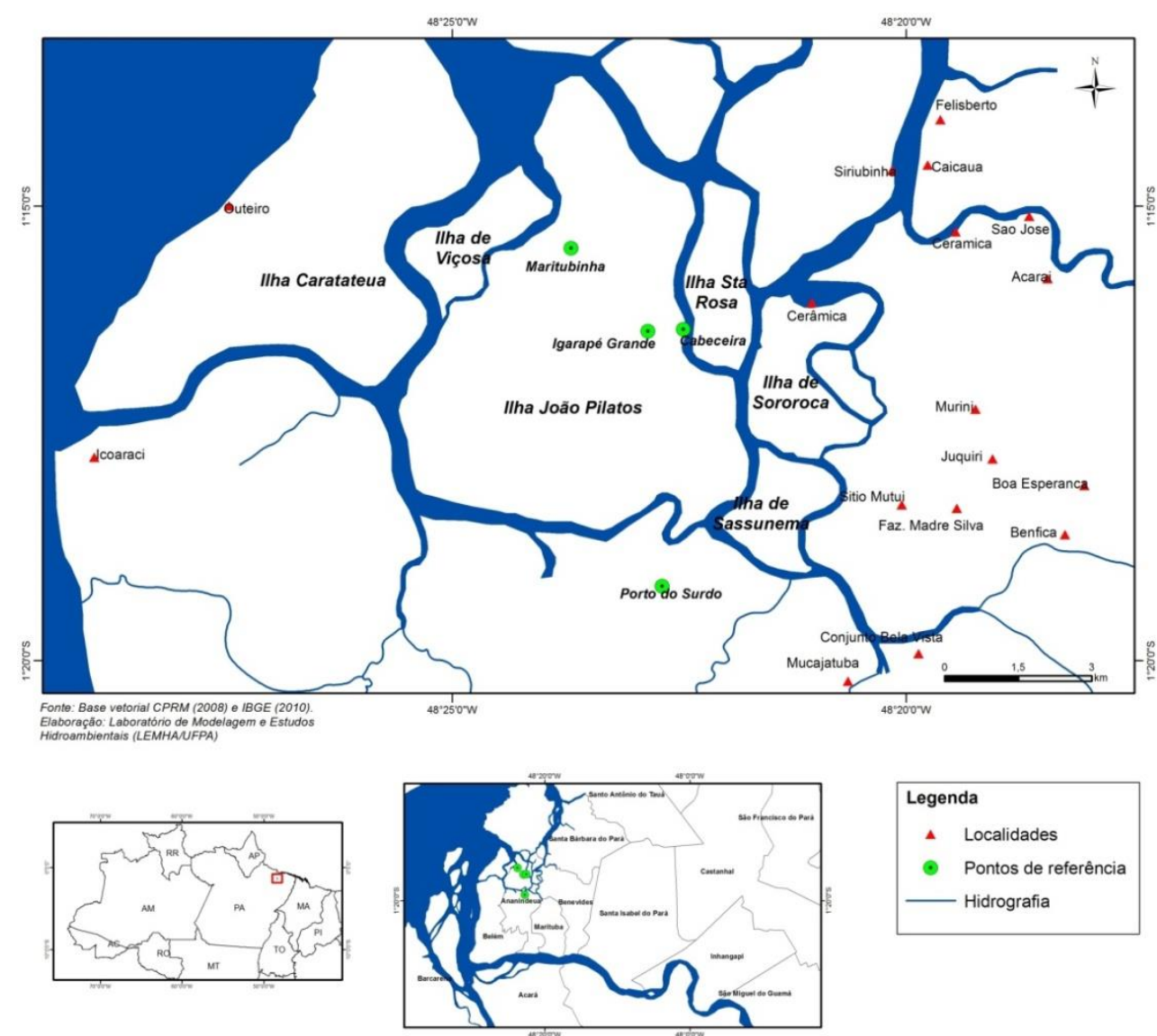

Fonte: Base Vetorial CPRM (2008) e IBGE (2010).

Elaboração: Laboratório de Modelagem e Estudos Hidroambientais

A cobertura vegetal da ilha João Pilatos caracteriza-se por floresta várzea representada, principalmente, pelas espécies: açaí (Euterpe oleracea Mart.), buriti (Mauritia flexuosa L. f.), ucuuba (Virola surinamensis Warb.), andiroba (Carapa guianensis Aubl.), samauma (Ceiba pentandra L. Gaertn.), louro (Nectandra amazonum Nees), assacu (Hura crepitans L.) etc. Apresenta o clima típico da região amazônica,

6 Fonte: Incra, 2011. 
quente e úmido, com chuvas abundantes, média de $2.6927 \mathrm{~mm}$, e temperatura média anual em torno de $27^{\circ} \mathrm{C}$ (ANANINDEUA, 2013).

A comunidade Igarapé Grande é composta por quatro localidades, denominação estabelecida pelos moradores locais: Cabeceira, Bela Vista, Paraíso e Maritubinha. Nas localidades da Cabeceira e Bela Vista vivem 10 famílias, no Paraíso residem 36 famílias e em Maritubinha, 15, totalizando 71 famílias 7 . 0 acesso à ilha de João Pilatos se dá pelo Porto do Surdo, localizado no bairro do Curuçambá - Ananindeua, ou Porto do Fidélis, em Outeiro (ANANINDEUA, 2013).

A comunidade Igarapé Grande foi escolhida por abrigar famílias que realizam atividades agrícolas e por apresentar um histórico de ocupação entre 100 e 150 anos $^{8}$.

A coleta de dados ocorreu por intermédio de entrevistas (informais e semiestruturadas) e observação participante com anotações em caderno de campo e registro audiovisuais, mediante autorização formalizada por meio da assinatura de "Termo de Livre Consentimento e Esclarecido".

Para tal, selecionou-se um informante principal (ALBUQUERQUE et al., 2010b) para orientação nas caminhadas e viagens de rabeta ${ }^{9}$ pela comunidade e indicação das famílias que desenvolviam atividades agroextrativistas. Sobre isso, ressalta-se que, na maioria dos casos, entrevistou-se somente um dos membros da família, que era apontado pelos próprios pares. Também foi aplicada a técnica bola de neve (BAILEY, 1994), na qual os informantes, ao término da entrevista, indicavam outros sujeitos para pesquisa.

As entrevistas informais eram realizadas de forma espontânea em atividades cotidianas, como momentos de viagens no barco escolar, nas rabetas e em caminhadas. Elas não foram gravadas, mas assim que possível, tomava-se notas em caderno de campo. Informalmente, entrevistou-se 14 sujeitos, sendo que alguns eram moradores de outras comunidades (três da comunidade de João Pilatos) e até mesmo de outras ilhas (dois da ilha de Santa Rosa). Estes dois últimos residiram na comunidade Igarapé Grande.

As entrevistas semiestruturadas seguiram um roteiro elaborado previamente, o qual constava de perguntas relacionadas à identificação dos sujeitos entrevistados (idade, sexo, escolaridade, dentre outros), e aspectos da atividade agrícola (espécies cultivadas, sistema de cultivo, distribuição das espécies, tempo de pousio, tipo de mão de obra etc.) desenvolvida por eles (ALBUQUERQUE et al., 2010a). Neste caso, o total

\footnotetext{
7 Fonte: dados da Associação dos Moradores e Pequenos Produtores Rurais da llha de Igarapé Grande (AMPIG).

8 Fonte: relato de entrevistas.

9 Canoa de madeira acoplada a um motor de baixa potência.
} 
de sujeitos entrevistados foi nove, sendo três da localidade de Maritubinha, cinco da Cabeceira e um do Paraíso ${ }^{10}$.

$\mathrm{Na}$ observação participante, foram registradas análises prévias, impressões, observações de comportamento, registros de falas em conversas informais, desenhos esquemáticos, atividades diárias, seguindo uma lógica temporal com base na descrição de Albuquerque et al. (2010a).

Para análise de dados, utilizou-se a técnica de análise de conteúdo, a qual "visa decompor as unidades léxicas ou temáticas de um texto, codificadas sobre algumas categorias, compostas por indicadores que permitam uma enumeração das unidades e, a partir disso, estabelecer inferências generalizadoras" (CHIZZOTTI, 2011, p. 113). Dessa forma, foram levantadas todas as informações coletadas em caderno de campo e as falas dos sujeitos nas entrevistas e, com base no referencial teórico adotado, estabeleceram-se unidades de contexto e unidades de análise (MORAES, 1999).

As unidades de contexto estabelecidas foram: saberes ambientais ${ }^{11}$ e saberes sobre conservação da biodiversidade. Os saberes ambientais consistem no conhecimento acerca do ambiente voltado à produção agrícola. Por outro lado, os saberes sobre conversação da biodiversidade dizem respeito aos conhecimentos sobre práticas agrícolas que podem propiciar ou não a conservação da diversidade biológica.

As unidades de análise e contexto (Quadro 1) foram identificadas nas entrevistas transcritas e anotações em caderno por meio de um código de cores e numeração, no qual as unidades de análise foram distinguidas a partir de diferentes cores e as unidades de contexto, por um número. Este processo de codificação visa auxiliar o pesquisador identificar as informações no material analisado de forma mais célere.

Quadro 1. Unidades de análise estabelecidas em relação aos saberes ambientais e saberes sobre conservação da biodiversidade

\begin{tabular}{|l|l|}
\hline \multicolumn{2}{|c|}{ Unidades de análise } \\
\hline Sistema de cultivo & Área escolhida para plantio \\
\hline Obtenção de mudas/sementes & Tempo de pousio \\
\hline Período do plantio & Áreas sem cultivo \\
\hline
\end{tabular}

10 Não foram realizadas entrevistas com sujeitos da localidade Bela Vista, pois eles não foram apontados como agricultores, mas sujeitos que exerciam atividades, sobretudo ligadas à pesca.

11 Esta unidade de contexto foi estabelecida tomando como base o trabalho de Diniz et al. (2012). 
Procedimentos/técnicas

Fonte: Elaborado pelos autores a partir do relato das entrevistas, anotações do caderno de campo e referencial teórico adotado.

Dessa maneira, estruturaram-se os resultados da seguinte forma: modo de vida da comunidade em geral, caracterização dos agricultores e identificação de atividades de produção agrícola relacionadas aos saberes sobre conservação da biodiversidade.

\section{RESULTADOS E DISCUSSÃO}

\subsection{0 modo de vida dos moradores da comunidade Igarapé Grande}

Os moradores da comunidade Igarapé Grande vivem das atividades da pesca, agricultura e extrativismo vegetal, com destaque para a extração do açaí e, em menor escala, do artesanato (utilitário e decorativo), avicultura (criação de galinhas e perus), pecuária12 e caça13. Entretanto, há moradores que possuem outras fontes de renda, como aposentadoria, pensão e funcionalismo público.

A maioria dos ribeirinhos tem um histórico de ocupação antigo na ilha e são descendentes de Domiciano Farias de Ramos, entre 100 e 150 anos ${ }^{14}$, fundador da comunidade Igarapé Grande. No ano de 2005, a área, não somente da comunidade Igarapé Grande, mas de toda ilha João Pilatos, foi estabelecida como um assentamento, especificamente, como Projeto de Assentamento Agroextrativista - PAE João Pilatos, pelo Instituto Nacional de Colonização e Reforma Agrária - Incra. A iniciativa partiu dos próprios ribeirinhos, visto que eles não possuíam títulos de suas terras e temiam perdê-las.

Após a demarcação das terras e a "Concessão de Uso", o financiamento oriundo do Incra permitiu aos moradores construir e reformar as casas, receber ferramentas de trabalho, sistema de eletrificação e abastecimento de água. O projeto ainda prevê, na segunda fase de implantação, provimento de recursos do Programa Nacional de Agricultura Familiar - Pronaf para fortalecimento das atividades produtivas locais.

\footnotetext{
12 Somente um morador possui uma pequena criação de gado bovino (entre 3 a 5 cabeças).

13 Entre os entrevistados, identificaram-se somente dois moradores que caçavam, sobretudo, tatu e paca.

14 Dado da Associação dos Moradores e Pequenos Produtores Rurais da Ilha de Igarapé Grande (AMPIG).
} 
Mesmo com as melhorias na comunidade, os ribeirinhos ainda carecem de assistência a alguns serviços básicos, como assistência à saúde, pois não há um posto médico na ilha; segurança, visto que constantemente são relatados roubos e furtos de piratas; e transporte público, já que não há qualquer embarcação coletiva ${ }^{15}$ que garanta 0 deslocamento dos moradores, dificultando o acesso a outras ilhas e à faixa continental de Ananindeua.

Em relação à educação, existe uma escola situada na localidade de Paraíso que atendia alunos do ensino fundamental e médio das quatro localidades da comunidade Igarapé Grande, bem como das demais comunidades da llha de João Pilatos, de ilhas próximas e do bairro Curuçambá (área continental). No entanto, durante o percurso desta pesquisa, o ensino médio foi extinto da escola. Sendo assim, muitos estudantes não o concluíram e outros se deslocaram para a o Município de Benevides, a fim de concluírem os estudos.

\subsection{Os agricultores da comunidade Igarapé Grande}

Dos agricultores de Igarapé Grande entrevistados, cinco são do sexo masculino e quatro do sexo feminino, indicando uma distribuição igualitária da atividade entre os gêneros. Esses dados corroboram com os estudos de Simonian (2006), Machado (2007) e Sousa e Silva (2012), que apontam para ampliação do papel da mulher no meio rural, passando de meramente reprodutora para produtora em diversas atividades.

Com relação à faixa etária, a maioria dos entrevistados (cinco) tem mais de 60 anos, quase todos aposentados (quatro) que continuam realizando seus cultivos agrícolas. O estudo realizado por Beltrão et al. (2005) também identificou essa tendência entre os idosos do meio rural, a partir dos dados da Pesquisa Nacional de Amostras por Domicílio PNAD de 2002. Os demais entrevistados (quatro) possuem entre 32 a 59 anos.

O nível de escolaridade dos agricultores restringe-se ao ensino fundamental incompleto (seis) e três são analfabetos. A pouca escolaridade ou analfabetismo é uma realidade presente no meio rural, visto que, historicamente, estas populações não são assistidas educacionalmente (FERRARO, 2012).

Do total dos entrevistados, sete são nativos da ilha de João Pilatos. Os demais são oriundos de localidades próximas à região das ilhas de Ananindeua: São Paulo das Pedrinhas - Santa Bárbara (um) e

\footnotetext{
15 Existe um barco escolar que transporta alunos e professores que, algumas vezes, também é utilizado pelos moradores que não possuem embarcações próprias.
} 
Murinim - Benfica (um), e residem na comunidade Igarapé Grande aproximadamente 50 e 20 anos, respectivamente.

No que diz respeito aos núcleos familiares, a maioria das unidades de concessão ${ }^{16}$ é composta por mais de uma residência, na qual a residência principal é a dos pais que, em média, contém 3,3 integrantes, sendo estes os pais, os filhos, os netos e os agregados (compadres). As residências adjacentes são pertencentes aos filhos/filhas e/ou aos sobrinhos que ganharam o espaço após constituírem família.

É comum, em alguns períodos do ano, os núcleos familiares adjacentes se reunirem em mutirão para executarem mais rapidamente uma determinada tarefa, por exemplo, na abertura de uma roça, na colheita e produção da farinha. Nesses casos, estabelecem-se acordos entre pais, filhos e compadres sobre a repartição da produção e troca de dias de trabalho. A prática de ajuda mútua e solidariedade no meio rural são relatadas também em outros estudos (OLIVEIRA, 2008; SEOANE et al., 2013).

Os indivíduos entrevistados não são exclusivamente agricultores, pois exercem múltiplas funções, isto é, são pescadores, extrativistas de produtos não madeireiros e madeireiros, criadores de animais (principalmente aves) e artesãos. Essa multiplicidade de tarefas está relacionada aos aspectos ambientais de clima (períodos chuvoso e seco) que impõe uma sazonalidade determinante em períodos de safra e entressafra. Em outras palavras, quando há escassez de um recurso, amplia-se a força de trabalho exercida em outra(s) atividade(s) e viceversa.

Pereira (2011) também identificou um exercício múltiplo de atividades entre os ribeirinhos das comunidades existentes nas Reservas de Desenvolvimento Sustentável - RDS de Amanã e Mamirauá e acrescenta que esta associação de atividades, para as comunidades ribeirinhas da Amazônia, está relacionada, além disso, a valores culturais e sociais.

A atividade artesanal abrange a produção de artefatos para pesca (matapi, viveiros e redes de pesca), produção da farinha (tipiti) e extração do açaí (paneiros), afora o artesanato decorativo e doméstico. Essa é uma prática desenvolvida por diversas comunidades na Amazônia, sendo que, em alguns locais, representa importante fonte de geração de renda e comércio (SANTOS; COELHO-FERREIRA, 2011). No caso do artesanato em Igarapé Grande, a produção desenvolvida tanto por homens, quanto mulheres é uma alternativa de complementação de renda e de suporte às demais atividades, tendo em vista a produção de ferramentas. Vale ressaltar que a produção artesanal possui aspectos

\footnotetext{
16 Lotes de terra demarcados pelo Incra.
} 
culturais importantes, visto que diversos artefatos são herança dos primeiros povos e habitantes da região (SOUSA, 2009).

\subsection{Atividade agrícola dos moradores de Igarapé Grande e sua relação com a conservação da biodiversidade}

O principal sistema de cultivo dos agricultores de Igarapé Grande é a roça, na qual se cultiva, sobretudo, variedades da espécie Manihot esculenta Crantz, popularmente conhecidas como mandioca e macaxeira (Tabela 1). A predominância dessa espécie também é relatada em outros estudos situados na região amazônica (PEREIRA et al., 2006; LIMA et al., 2012; LIMA et al., 2013).

Tabela 1. Espécies vegetais cultivadas pelos agricultores de Igarapé Grande (Ut: utilidade; $\mathrm{N}^{\circ}$ de cit: número de citações; A: Alimentação; $\mathrm{M}$ :

Medicinal)/*Espécies que se cultivam mais de uma variedade

\begin{tabular}{|c|c|c|c|}
\hline Nome Vulgar & Nome Científico & Ut. & $\mathrm{N}^{\circ}$ de Cit. \\
\hline Mandioca* & Manihot esculenta Crantz & A & 9 \\
\hline Cupuaçu & Theobroma grandiflorum (Wild. Ex Spreng.) Schum & A & 6 \\
\hline Açaí & Euterpe oleraceae Mart. & $A$ & 6 \\
\hline Banana* & Musa ssp L. & $A$ & 6 \\
\hline Milho* & Zea mays L. & A & 6 \\
\hline Maxixe & Cucumis anguria $\mathrm{L}$. & $A$ & 6 \\
\hline Jerimum & Cucurbita L. & A & 4 \\
\hline Limão comum* & Citrus X limon (L.) Burm. & A & 3 \\
\hline Arroz & Oryza sativa $\mathrm{L}$. & $A$ & 3 \\
\hline Caruru & Amaranthus viridis $\mathrm{L}$. & $\mathrm{A} / \mathrm{M}$ & 3 \\
\hline Abacate & Persea americana Mill. & A & 2 \\
\hline Uchi & Endopleura uchi (Huber) Cuatr. & A & 2 \\
\hline Ananã & Ananas comosus (L.) Merril & A & 2 \\
\hline Melancia & Citrullus lanatus (Thunb.) Matsum. \& Nakai & A & 2 \\
\hline Côco & Cocos nucifera $\mathrm{L}$. & $A$ & 2 \\
\hline Urucum & Bixa orellana $\mathrm{L}$. & $\mathrm{A} / \mathrm{M}$ & 2 \\
\hline Tomate & Solanum Iycopersicum L. & A & 2 \\
\hline Erva-cidreira & Lippia alba (Mill.) N.E.Br. ex Britton & M & 2 \\
\hline Sucuriju & Mikania lindleyana DC. & M & 2 \\
\hline Feijão & Phaseolus vulgaris $\mathrm{L}$. & A & 2 \\
\hline Quiabo & Abelmoschus esculentus (L.) Moench & $A$ & 3 \\
\hline Pupunha & Bactris gasipaes Kunth & A & 1 \\
\hline Bacuri & Platonia insignis Mart. & A & 1 \\
\hline Bacabi & Oenocarpus bacaba Mart. & A & 1 \\
\hline Manga & Magifera indica L. & $A$ & 1 \\
\hline Mamão & Carica papaya. L. & A & 1 \\
\hline Laranja & Citrus $X$ sinensis (L.) Osbeck & A & 1 \\
\hline
\end{tabular}


Neriane N. da Hora, Hélio R. Ferreira. Filho, Ana Cláudia C. T. Martins, Maria J. C. F. Fonseca

A Brassica oleracea L.

A 1

Redes (St. Cruz Sul, Online), v. 20, n² 2, p. 308 - 335, maio/ago. 2015321 
Continuação

\begin{tabular}{lllc}
\hline Nome Vulgar & Nome Científico & Ut. & No de Cit. $^{\circ}$ \\
\hline Pimentinha & Capsicum ssp L. & $\mathrm{A}$ & 1 \\
Puçari & Não Identificada & $\mathrm{A}$ & 1 \\
Cheiro-verde & Petroselinum crispum (Mill.) Nym. & $\mathrm{A}$ & 1 \\
Gergelim & Sesamum indicum D.C. & $\mathrm{M}$ & 1 \\
Eparex & Não identificada & $\mathrm{M}$ & 1 \\
Gengibre & Zingiber officinale Roscoe & $\mathrm{M}$ & 1 \\
Unha de Gato & Uncaria spp.Schreb & $\mathrm{M}$ & 1 \\
Pé de Galinha & Eleusine indica L. Gaertn & $\mathrm{M}$ & 1 \\
Coramina & Pedilanthus tithymaloides Poit. & $\mathrm{M}$ & 1 \\
Canarana & Panicum L. & $\mathrm{M}$ & 1 \\
Corrente & Pfaffia glomerata (Spreng.) Pedersen & $\mathrm{M}$ & 1 \\
Sacaca & Croton cajucara Benth. & $\mathrm{M}$ & 1 \\
Camomila & Matricaria recutita L. & $\mathrm{M}$ & 1 \\
Boldo & Plectranthus barbatus Andrews & $\mathrm{M}$ & 1 \\
Capim-marinho & Cymbopogon Spreng. & $\mathrm{M}$ & 1 \\
Juru & Não Identificada & $\mathrm{M}$ & 1 \\
Arruda & Ruta graveolens L. & $\mathrm{M}$ & 1 \\
\hline
\end{tabular}

Maxixe (Cucumis anguria L.) e milho (Zea mays L.) também são espécies representativas cultivadas nos roçados de Igarapé Grande, afora outras espécies em menor escala (Tabela 1). Os cultivos destas ocorrem misturados às espécies de mandioca/macaxeira, isto é, não seguem um padrão de alinhamento e/ou espaçamento agronômico, o que, na literatura, denomina-se de plantio tradicional em miscelânea (NODA et al., 2007).

O plantio de Cucumis anguria L. é considerado não convencional pelo Ministério da Agricultura, Pecuária e Abastecimento - MAPA (BRASIL, 2010), contudo, na região amazônica, é bastante comum, pois esta espécie, embora exótica, adaptou-se bem ao clima da região (PIMENTEL, 1985). O milho (Zea mays L.), por outro lado, é utilizado especialmente como recurso alimentar para as aves criadas nos quintais dos agricultores.

Os quintais são áreas ao redor das casas, nas quais são cultivadas espécies florestais e arbustivas associadas a espécies agrícolas anuais e perenes (Tabela 1), por isso são classificados como sistemas agroflorestais (SAFs) (FERNANDES; NAIR, 1986). No caso de Igarapé Grande, predominam o plantio de açaí (Euterpe oleracea Mart.) e cupuaçu (Theobroma grandiflorum (Wild. Ex Spreng.) Schum). Além disso, como já citado, abrigam criações de animais, principalmente de aves (galinhas e perus), que crescem livres ou em pequenos cercados, assegurando uma alternativa de segurança alimentar a partir da 
comercialização do excedente ou do próprio consumo, como também identificado por Tosetto et al. (2013).

A utilização de sistemas agroflorestais, sobretudo os quintais, são frequentes modelos de uso da terra adotado por agricultores familiares amazônicos (CASTRO et al., 2009; MARTINS et al., 2012; VIEIRA et al., 2012). A diversificação e a multiestratificação de espécies dos quintais podem operar efeitos benéficos no ambiente (FERNADES; NAIR, 1986; NAIR, 1993), como maior proteção e fertilidade do solo, ampliação de interações ecológicas (ABDO et al., 2008), provisão de habitats secundários para espécies tolerantes a certos níveis de distúrbios, redução da pressão sobre áreas de floresta primária, conexão de remanescentes florestais (MCNEELY, SCHROTH, 2006) e conservação da diversidade genética por meio de bancos de sementes (GALUZZI et al. 2010).

Assim sendo, registrou-se 46 espécies cultivadas tanto nos roçados, quanto nos quintais agroflorestais, com a média de espécies por agricultor correspondente a 11,3 espécies. Vale frisar que, em algumas espécies, é explorado o cultivo de mais de uma variedade, como é o caso da Manihot esculenta Crantz.

Essa diversificação, inter e intraespecífica, é característica da agricultura tradicional, a exemplo do trabalho de Costa e Mitja (2010) que registraram 97 espécies cultivadas nos pomares e 18 espécies nas capoeiras de ribeirinhos no Amazonas; Vieira et al. (2007) registraram 38 espécies cultivadas em Sistemas Agroflorestais - SAFs de agricultores no Pará. E quanto à diversidade intraespecífica, Emperaire e Eloy (2008) catalogaram 150 e 10 variedades de mandioca e macaxeira, respectivamente; e Lima et al. (2013), 52 variedades de mandioca.

O policultivo proporciona benefícios ao agricultor, uma vez que espécies consorciadas promovem maior prevenção às pragas por intermédio da cooperação entre os seus mecanismos de defesa. Por conseguinte, resulta em maior produtividade e segurança alimentar (ALTIERI, 2004). Somam-se, ainda, vantagens ambientais, como aumento das relações ecológicas, da ciclagem e retenção de nutrientes e da taxa de resiliência do sistema, regulação climática e hídrica e depuração da água (JACKSON et al., 2007; PASCUAL; PERRINGS, 2007).

A variabilidade intraespecífica, sobretudo da espécie Manihot esculenta Crantz, é produto de práticas culturais de permutação de mudas entre roçados antigos e novos, intra e intercomunitários (ROBERT et al., 2012), bem como, por meio da seleção artificial realizada pelas comunidades amazônicas (MARTINS, 2005), aspectos que também prevalecem entre os agricultores de Igarapé (Quadro 2).

A prática de obtenção de mudas/sementes a partir dos círculos sociais é importante para a conservação da agrobiodiversidade, pois possibilita a manutenção e ampliação do pool genético das espécies 
(LEITE et al., 2012). Diferentemente da homogeneização de cultivos agrícolas por meio de sementes comerciais, que impacta não somente a biodiversidade - silvestre e domesticada - (MEA, 2005), mas também acarreta erosão dos saberes associados à mesma (ROBERT et al., 2012). 


\section{Quadro 2. Unidades de análise e sua relação com as unidades de contexto}

\begin{tabular}{|c|c|c|}
\hline & Saberes relacionados ao ambiente & $\begin{array}{c}\text { Saberes (práticas) que propiciam a } \\
\text { conservação da biodiversidade }\end{array}$ \\
\hline Sistema de Cultivo & & $\begin{array}{l}\text { - Quintais agroflorestais. } \\
\text { - Roças diversificadas. } \\
\text { - Enriquecimento da capoeira. }\end{array}$ \\
\hline $\begin{array}{l}\text { Obtenção de } \\
\text { mudas/sementes }\end{array}$ & & $\begin{array}{l}\text { - Mudas do plantio anterior. } \\
\text { - Mudas de roçados vizinhos. }\end{array}$ \\
\hline $\begin{array}{l}\text { Período do } \\
\text { plantio/safra }\end{array}$ & $\begin{array}{l}\text { - Preferência por algumas fases lunares, pois } \\
\text { aumentam a produção. } \\
\text { - Evitam o plantio em quarto minguante, pois } \\
\text { prejudica o crescimento dos cultivos agrícolas. } \\
\text { - Para evitar pragas, deve-se plantar na lua } \\
\text { nova. } \\
\text { - Devem-se fazer a derrubada e queima antes } \\
\text { da chegada das chuvas. } \\
\text { - O plantio da mandioca no período seco intenso } \\
\text { pode levar à perda da produção. Nesse caso, } \\
\text { deve-se plantá-la um pouco antes da chegada } \\
\text { das chuvas. } \\
\text { - O plantio do açaí e cupuaçu deve ser feito no } \\
\text { período das chuvas. } \\
\text { - O milho deve ser plantado um pouco antes das } \\
\text { chuvas, porque ele não suporta altas } \\
\text { temperaturas. }\end{array}$ & \\
\hline Procedimentos/técnicas & $\begin{array}{l}\text { - Devem-se capinar duas a três vezes para evitar } \\
\text { que ervas daninha cresçam e compitam com os } \\
\text { cultivos agrícolas. } \\
\text { - Capinar todo o terreno, incluindo área ao redor } \\
\text { da casa, diminui a fertilidade da terra. } \\
\text { - Deve-se retirar os "tocos" (raízes de grande } \\
\text { porte das árvores derrubadas) para não impedir } \\
\text { a mandioca de crescer. } \\
\text { - Quanto ao cupuaçu, devem-se podar os galhos } \\
\text { para que ele possa produzir-se por muitos anos. } \\
\text { - Para produção anual do açaizeiro e } \\
\text { cupuaçuzeiro, deve-se fazer adubação } \\
\text { constante. } \\
\text { - O espaçamento no plantio do açaí deve ser } \\
\text { entre 8m e } 10 \text { m. Caso contrário, não ocorrerá } \\
\text { uma boa produção. } \\
\text { - Pode-se aproveitar os resíduos da capina, } \\
\text { jogando-os em um buraco para decompor. Em } \\
\text { alguns anos, pode-se plantar alguma espécie no } \\
\text { local, que crescerá. } \\
\text { - Onde o solo é bastante compacto, deve-se } \\
\text { revirá-lo para a raiz poder se espalhar. Caso } \\
\text { contrário, os cultivos agrícolas, principalmente, a } \\
\text { mandioca, não crescerão. }\end{array}$ & $\begin{array}{l}\text { - Aproveitamento da madeira } \\
\text { grossa para produção de carvão. } \\
\text { - Limpeza ao redor da área da } \\
\text { queima para não ultrapassagem do } \\
\text { fogo. } \\
\text { - Adubação orgânica (biomassa } \\
\text { proveniente da capina). }\end{array}$ \\
\hline $\begin{array}{l}\text { Escolha da área para } \\
\text { plantar }\end{array}$ & $\begin{array}{l}\text { - Onde a terra fica inundada, não é propício para } \\
\text { plantar, porque a mandioca morre. } \\
\text { - Na terra amarela, solo com menor grau de } \\
\text { umidade, é próprio para plantar. } \\
\text { - Os antigos buracos de forno (para queimar }\end{array}$ & $\begin{array}{l}\text { - Deve-se plantar em áreas com } \\
\text { madeiras baixas, onde já ocorreu } \\
\text { plantio de roças, as chamadas } \\
\text { capoeiras. } \\
\text { - Áreas com madeira alta são }\end{array}$ \\
\hline
\end{tabular}




\begin{tabular}{|c|c|c|}
\hline & $\begin{array}{l}\text { lenha) podem ser aproveitados para plantar } \\
\text { bananeira. } \\
\text { - Não é bom plantar em solo arenoso, pois ele } \\
\text { se aquece bastante, o que pode prejudicar o } \\
\text { plantio. } \\
\text { - Na terra geral, a produção das frutíferas é } \\
\text { constante; na terra firme, somente de ano em } \\
\text { ano. }\end{array}$ & $\begin{array}{l}\text { evitadas. } \\
\text { - Roças em áreas de capoeira fina } \\
\text { (fase inicial da sucessão } \\
\text { secundária) produzem muitas } \\
\text { ervas daninhas, por isso não é } \\
\text { aconselhável plantar nestas áreas. } \\
\text { - Não se deve plantar em áreas } \\
\text { passíveis de inundação porque a } \\
\text { mandioca não desenvolverá. } \\
\text { - Preferem plantar em áreas de } \\
\text { capoeira grossa (fase avançada da } \\
\text { vegetação secundária), pois } \\
\text { demanda menos esforço de } \\
\text { trabalho (capina). }\end{array}$ \\
\hline Tempo de pousio & $\begin{array}{l}\text { - Quanto maior tempo de pousio, mais fértil fica } \\
\text { o solo. }\end{array}$ & $\begin{array}{l}\text { - Descanso da terra é importante } \\
\text { para o processo de sucessão } \\
\text { ecológica (regeneração ambiental). } \\
\text { - Quando o tempo de pousio é } \\
\text { longo são produzidas capoeiras } \\
\text { grossas (áreas de maior acúmulo } \\
\text { de biomassa e liteira). }\end{array}$ \\
\hline Áreas sem cultivo & $\begin{array}{l}\text { - São importantes, pois o desmatamento } \\
\text { provoca escassez de chuva, morte de peixes e } \\
\text { aumento da temperatura. }\end{array}$ & $\begin{array}{l}\text { - Derrubada somente para o } \\
\text { plantio. } \\
\text { - Deve-se evitar desmatar para a } \\
\text { preservação dos rios. } \\
\text { - São importantes, pois o } \\
\text { desmatamento provoca escassez } \\
\text { de chuva, morte de peixes e } \\
\text { aumento da temperatura. }\end{array}$ \\
\hline
\end{tabular}

Os roçados de Igarapé Grande caracterizam-se por apenas um ciclo de cultivo, sendo que "abandona-se" a área (pousio), na qual passa a desenvolver-se uma vegetação secundária (capoeira). Contudo, utiliza-se uma técnica de enriquecimento das capoeiras (Quadro 2), que consiste no plantio de espécies frutíferas, sobretudo o cupuaçu (Theobroma grandiflorum) e o açaí (Euterpe oleraceae), para aproveitamento da área, como se observa nesta fala:

Eu semeio, faço semear os caroços, assim, de cupuaçu, de urucum. Eu espalho, assim, tudinho no local, no chão mesmo assim [...]. Aí quando for botar um aqui, o outro ali, aí nesse vão aqui que vou pegar mandioca, já enterrei o cupuaçu. Quando eu arrancar a roça, o cupuaçu, já tá tudo aqui. Daqui mais um ano, daqui com cinco anos já tão no ponto deu aparar eles (entrevistado 03).

O plantio de açaí foi uma prática introduzida por técnicos da Empresa de Assistência Técnica e Extensão Rural - EMATER. Evidenciase, neste caso, que os saberes e práticas tradicionais não são estáticos, 
mas que podem sofrer inserções de outros conhecimentos (ALMEIDA, 2006). Os agricultores ampliaram a prática de cultivo nas capoeiras, utilizando também a espécie Euterpe oleraceae. Apesar disso, uma grande parte da produção ainda é proveniente da várzea, que é utilizada de forma coletiva.

$O$ enriquecimento de capoeiras também foi diagnosticado entre caboclos - ribeirinhos da comunidade Lago de Araras no Amazonas, sendo avaliado como uma alternativa sustentável, frente ao baixo período de pousio (três a cinco anos) empregado nas capoeiras (CASTRO et al., 2006), já que promove maior taxa de regeneração da vegetação secundária (BRIENZA JÚNIOR, 2012).

Partindo desse pressuposto, o enriquecimento das capoeiras em Igarapé Grande também pode ser considerado uma alternativa que reestabelece, em menor tempo, a vegetação secundária, uma vez que se registraram períodos de pousio entre três e dez anos. Nesse caso, os agricultores avaliam que o impacto do uso da terra é baixo, ao passo que colaboram para a recuperação das capoeiras. Resta saber, a real contribuição desse enriquecimento, visto que, dependendo das espécies escolhidas, o tempo da regeneração da floresta secundária pode ser diferente (BRIENZA JÚNIOR, 2012; WILLERDING; OLIVEIRA, 2005).

Mesmo que a vegetação secundária não seja enriquecida, as capoeiras possuem valor ecológico, pois funcionam como ambientes de regeneração da vegetação natural; sendo assim, não podem ser consideradas como áreas totalmente degradadas (ALMEIDA et al., 2010; PEREIRA; VIEIRA, 2001). Isso contrapõe a ideia de destinação de áreas desmatadas, o que inclui as capoeiras, para expansão da agricultura mecanizada e agropecuária (HOMMA, 2005).

Além disso, outro fator que contribui para considerar que a vegetação secundária pode estar se reestabelecendo em menor tempo é a preferência dos agricultores pela escolha de áreas com capoeira grossa (áreas de vegetação secundária avançada) para o plantio. Caso contrário, seria uma contradição os agricultores afirmarem que estão utilizando um menor tempo de pousio e, ao mesmo tempo, plantando em áreas de capoeira grossa.

A tendência de escolha das áreas de capoeira grossa é reforçada por meio dos saberes ambientais dos agricultores, pois reconhecem que tais áreas favorecem maior produtividade e são menos propensas à proliferação de ervas daninha (Quadro 2), fator ambiental já caracterizado na literatura (LUIZÃO et al., 2009). Soma-se a isso que a preferência por áreas de capoeira em detrimento das áreas de mata (denominada pelos agricultores como áreas de madeira alta) indica certa estabilidade da regeneração das áreas de capoeira em tempo hábil para novos ciclos de produção, assim como verificado pelo estudo de Richers (2010). 
O aproveitamento da madeira grossa das roças derrubadas para fabricação de carvão também diminui a pressão sobre a floresta primária. A extração madeireira abre clareiras no interior da floresta, provocando perturbações na dinâmica do ecossistema por meio do efeito de borda. Consequentemente, há aumento da taxa de luminosidade e vento para seu interior, afetando na distribuição e riqueza das espécies, o que pode ocasionar focos de incêndio (LUIZÃO et al., 2009).

A utilização da queima na abertura das roças é um fator de risco, como relatado em alguns trabalhos (NEPSTAD et al., 2008). Entretanto, verifica-se, entre os agricultores de Igarapé Grande, o cuidado com a limpeza da área em volta do local onde será ateado o fogo com o objetivo de impedir a expansão do mesmo para as áreas adjacentes. A queima, apesar de ser uma prática bastante antiga, que serve para incorporação de nutrientes da biomassa carbonizada ao solo (FEARNSIDE, 1989), tem sido debatida em termos de sua sustentabilidade. Seu uso frequente provoca perda da fertilidade do solo ao longo dos anos, sendo necessários períodos de pousio cada vez mais longos para regeneração ambiental. Além disso, discute-se o impacto dessa prática sobre o banco de sementes do solo (LEAL et al., 2006).

Portanto, defendem-se propostas de substituição da queima pela técnica de corte e trituração. Essa prática consiste no corte raso da vegetação e, posteriormente, trituração dela; após isso, deposita-se a biomassa triturada sobre o solo que, com o passar dos dias, sofre decomposição e libera nutrientes para ele (VEIGA et al., 2012). Apesar dessa prática ser vantajosa em termos ambientais, existem limitações financeiras para sua implementação por parte dos agricultores, visto que eles não possuem condições de adquirir máquinas para corte raso e trituração. Há possibilidade de fazer o corte e a trituração manualmente, entretanto exige-se maior força de trabalho, o que se torna uma dificuldade para esses indivíduos, pois a única mão de obra empregada é familiar.

Embora os agricultores não utilizem uma técnica de adubação de corte e trituração, eles utilizam uma prática tradicional e de menor custo, que consiste na utilização dos resíduos vegetais provenientes da capina. Hole et al. (2005) asseguram que a adubação orgânica, em substituição ao uso de insumos e fertilizantes inorgânicos, aliada a outras práticas, podem contribuir para maior diversidade de espécies nas paisagens agrícolas.

A prática da capina está relacionada a saberes ambientais ligados ao desenvolvimento do plantio e, segundo os agricultores, sua execução necessita de habilidades:

Quem capina mais é eu porque a maniva tá miúda e é um buraco lá, outro aqui, bem espaçoso, a gente não pode meter 
enxada logo, tem que ir devagar. Perto da maniva, a gente tem que parar, tirar todos capins, se não mata a maniva, aí bota aqueles capins tudo no pézinho dela, aí ela cresce rapidinho (entrevistado 05).

Os saberes ambientais perpassam, ainda, toda a relação dos agricultores com o uso da terra (Quadro 2). Eles saberes possibilitam, por exemplo, a construção de um calendário próprio de atividades (período do plantio de cada espécie, período da safra/colheita de cada espécie) não somente atrelado aos aspectos climáticos, mas também referentes à posição lunar. Tal relação é relatada por Altieri (2004, p. 34 ), que afirma que muitos agricultores "podem semear de acordo com a fase da lua, acreditando que há fases lunares de precipitação".

A área média de roça em Igarapé Grande corresponde a 0,67 ha. Este valor aproxima-se do valor ideal para agricultura de corte e queima de baixo impacto - 0,5 ha (EMPERAIRE; ELOY, 2008). Ademais, 0,67 ha aproxima-se dos valores encontrados no estudo de Richers (2010) para áreas de várzea, na qual a pressão para uso da terra é menor do que em áreas de terra firme.

O tipo de uso da terra implica na diversidade das florestas secundárias posteriores. Estudos revelam que florestas sucessionais sobre solos onde anteriormente havia pastagem ou se praticava a agricultura intensiva, a diversidade florística é menor do que sobre solos da agricultura de corte e queima (MORAN et al., 2000; PEREIRA; VEIRA, 2001).

As áreas sem cultivo são cruciais para a conservação da biodiversidade, sendo uma prerrogativa do Código Florestal - CFI brasileiro, denominada de Reserva Legal (AVANCI, 2009). Além disso, as matas ciliares acabam também sendo preservadas, tendo em vista 0 saber ambiental de que plantios próximos a áreas inundáveis acarretam em prejuízos agrícolas (Quadro 2), aspecto também retratado no CFI (STEFANELO, 2009). Verifica-se que os agricultores de Igarapé Grande compreendem essas relações, como demonstra esta fala:

Olha uma mata dessa aí, o cara não pode destruir tudo. Se não vai dar a seca, né? Como já deu aí, morre muita coisa aí, peixe é, peixe morre, não tem mais árvore, é só quentura (entrevistado 04).

Dessa forma, os ribeirinhos reconhecem que a conservação do ambiente está diretamente ligada à manutenção das suas atividades, e, consequentemente, procuram manejar a área de forma harmônica. 
Por fim, deve-se destacar que a principal vocação produtiva dos moradores de Igarapé Grande não é representada pela agricultura, tanto que, dentre 76 famílias, foram apontadas somente nove pelos informantes da pesquisa para a realização de entrevistas. Tal fato pode ser explicado pela localização da comunidade Igarapé Grande em um ambiente de várzea, onde a influência da pesca e extração do açaí é muito maior, fato também encontrado no estudo de Richers (2010).

Além disso, a produção proveniente do cultivo agrícola destinase, principalmente, ao autoconsumo. Diferentemente do extrativismo do açaí, em que parte é voltada para comercialização. A subsistência é um aspecto comum entre pequenos produtores tradicionais, na qual a lógica do mercado ainda não exerce influência significativa, o que gera maior sustentabilidade social e ambiental (LIMA; POZZOBON, 2005).

A produção agrícola em Igarapé Grande não vem produzindo grandes impactos na conservação da biodiversidade na ilha, visto que os principais processos de perda de biodiversidade são evitados, como desflorestamento de matas primárias, uso de insumos e fertilizantes agrícolas e destruição das matas ciliares. E ainda, utiliza-se de processos que provocam menor impacto sobre a biodiversidade, como diversificação das espécies agrícolas, multiestratificação e diversificação de espécies nos quintais, adubação orgânica, enriquecimento de capoeiras, dentre outros.

\section{CONSIDERAÇÕES FINAIS}

Os saberes ambientais expressam-se de forma mais ampla nos relatos dos agricultores. Esse fato era, de certa forma, esperado, visto que o conhecimento sobre o ambiente e sua dinâmica é importantíssimo para a sobrevivência e a reprodução do modo de vida dos entrevistados.

Os saberes ambientais estão fortemente ligados a alguns princípios da conservação da biodiversidade, como os saberes sobre tempo de pousio e crescimento da vegetação secundária e seus impactos no desenvolvimento do plantio. Além disso, percebeu-se saberes ligados diretamente à conservação, uma vez que os entrevistados reconhecem o impacto do desmatamento no equilíbrio ecológico e, consequentemente, na manutenção da biodiversidade.

De forma geral, os moradores de Igarapé Grande percebem a sua dependência dos recursos naturais e têm o entendimento das consequências da exploração desordenada. Por isso, procuram utilizar a biodiversidade para tão somente suprir suas necessidades de sobrevivência. Consideram a agricultura como uma atividade de subsistência que não afeta a dinâmica ambiental da ilha. 
Contudo, é preciso considerar que os agricultores percebem uma forte pressão do mercado para ampliação das fronteiras agrícolas na ilha de João Pilatos. E frente à valorização econômica de alguns produtos agrícolas (como a farinha), esses sujeitos vislumbram uma forma de emancipação e desenvolvimento. No entanto, são limitados pela baixa capacidade de investimento na atividade e pela reduzida mão de obra.

Sendo assim, faz-se necessária a formulação de políticas públicas que não somente atuem de forma restritiva, proibindo o uso dos recursos naturais, ou então, regulamentando suas atividades. É preciso compreender as demandas dessas populações ribeirinhas, seu modo de vida e os meios que utilizam para sua reprodução física, cultural e social.

A realização deste estudo, juntamente com outros que enfoquem as demais atividades realizadas pela comunidade, aliados a estudos econômicos, poderiam indicar soluções mais favoráveis ao desenvolvimento social, econômico e cultural da comunidade Igarapé Grande.

Pesquisas que tratem do uso das espécies florestais (madeireiras e não madeireiras) e da aquicultura também poderão apontar eventuais práticas locais relacionadas à conservação da biodiversidade. Somente com informações acerca de todas as atividades realizadas pelos grupos humanos da llha João Pilatos é que será possível caracterizar um panorama conservacionista e de desenvolvimento local.

As comunidades das ilhas da RMB, como dependentes diretas do meio ambiente e sua biodiversidade, são as primeiras a desejarem a conservação, não somente porque significa um ambiente de provisão de recursos naturais, mas também pelo seu valor cultural, religioso e ancestral.

\section{REFERÊNCIAS}

ABDO, M. T. V. N.; VALERI, S. V.; MARTINS, A. L. M. Sistemas agroflorestais e agricultura familiar: uma parceria interessante. Revista Tecnologia e Inovação Agropecuária, v. 1, n. 2, p. 50-59, 2008.

ALbUQUerQue, U. P.; LUCENA, R. F. P.; ALENCAR, N. L. Métodos e Técnicas para Coleta de Dados Etnobiológicos. In: ALBUQUERQUE, U. P.; LUCENA, R. F. P.; CUNHA, L. V. F. C. Métodos e Técnicas na Pesquisa Etnobiológica e Etnoecológica. Recife, PE: NUPEEA, 2010a, p. 41-64. 
ALBUQUERQUE, U. P.; LUCENA, R. F. P.; LINS NETO, E. M. F. Seleção dos participantes da pesquisa. In: ALBUQUERQUE, U. P.; LUCENA, R. F. P.; CUNHA, L. V. F. C. Métodos e Técnicas na Pesquisa Etnobiológica e Etnoecológica. Recife, PE: NUPEEA, 2010b, p. 23-37.

ALMEIDA, A. F.; JARDIM, M. A. G. A utilização de espécies arbóreas da floresta de várzea da llha de Sororoca, Ananindeua, Pará, Brasil por moradores locais. Revista Brasileira de Ciências Ambientais, n. 23, p. 48-54, 2012.

ALMEIDA, A. W. B. Arqueologia da tradição: uma apresentação da coleção "Tradição e ordenamento jurídico". In: SHIRAISHI NETO, J. Leis do babaçu livre: práticas jurídicas do coco babaçu e normas correlatas. Manaus: Tradição e Ordenamento Jurídico, 2006, p. 7-12.

ALMEIDA, C. A. et al. Estimativa da vegetação secundária na Amazônia Legal Brasileira. Acta Amazonica, v. 40, n. 2, p. 289-302, 2010.

ALTIERI, M. Agroecologia: a dinâmica produtiva da agricultura sustentável. 4. ed. Porto Alegre: Editora da UFRGS, 2004, 120 p.

AMARAL, D. D. et al. Cheklist da flora arbórea de remanescentes florestais da região metropolitana de Belém e valor histórico dos fragmentos, Pará, Brasil. Boletim do Museu Paraense Emílio Goeldi, Ciências Naturais, v. 4, n. 3, p. 231-289, 2009.

AMOROZO, M. C. M.; VIERTLER, R. B. A abordagem qualitativa na coleta e análise de dados em etnobiologia e etnoecologia. In: ALBUQUERQUE, U. P.; LUCENA, R. F. P.; CUNHA, L. V. F. C. Métodos e Técnicas na Pesquisa Etnobiológica e Etnoecológica. Recife, PE: NUPEEA, 2010, p. 67-82.

ANANINDEUA. Plano de desenvolvimento rural sustentável para o município de Ananindeua. Diário Oficial do Município de Ananindeua, 30jan. 2013. 
AVANCI, T. F. S. A reserva legal como instrumento de efetividade da proteção da biodiversidade. Revista USCS - Direito, v. 10, n. 17, p. 187209, 2009.

BALÉE, W. Footprint of the Forest Ka'apor Ethnobotany. the historical ecology of plant utilization by amazonian people. Nova lorque: Columbia Univ. Press, 1994, 416 p.

BAILEY, K. Methods of social research. 4 ed. New York: The Free Press, 1994, $588 \mathrm{p}$.

BELTRÃO, K. I.; CAMARANO, A. A.; MELLO, J. L. Mudanças nas condições de vida dos idosos rurais brasileiros: resultados não esperados dos avanços da seguridade social. Texto para Discussão, n. 1066, p. 1-26, Instituto de Pesquisa Econômica e Aplicada - IPEA: Rio de Janeiro, 2005.

BRIENZA JÚNIOR, S. Enriquecimento de florestas secundárias como tecnologia de produção sustentável na agricultura familiar. Boletim do Museu Paraense Emílio Goeldi, Ciências Naturais, v. 7, n. 3, p. 331-337, 2012.

BOHENSKY, E. L.; MARU, Y. Indigenous knowledge, science and resilience: what have we learned from a decade of international literature on "integration"? Ecology and Society, n. 16, v. 4, 2011.

BRASIL. MINISTÉRIO DA AGRICULTURA, PECUÁRIA E ABASTECIMENTO MAPA. Manual de hortaliças não-convencionais. Brasília: MAPA, 2010, $94 \mathrm{p}$.

Decreto $n^{\circ}$ 6040, de 07 de fevereiro de 2007. Institui a Política Nacional de Desenvolvimento dos Povos e Comunidades Tradicionais. Diário Oficial da União, Brasília, DF, 08 fev. 2007. Seção 1, n. 28, p. 316.

CAMACHO, L. D. et al. Traditional forest conservation knowledge/Technologies in the Cordillera, Northern Philippines. Forest Policy and Economics, 22, p. 3-8, 2012. 
CASTRO, A. P.; FRAXE, T. J. P.; LIMA, H. N. O etnoconhecimento dos caboclos-ribeirinhos no manejo ecológico do solo em uma comunidade amazônica. Somanlu - Revista de Estudos Amazônicos, v. 6, n. 2, p. 105-118, 2006.

CASTRO, A. P. et al. Os sistemas agroflorestais como alternativa de sustentabilidade em ecossistemas de várzea no Amazonas. Acta Amazonica, v. 39, n. 2, p. 279-288, 2009.

CHARNLEY, S.; FISCHER, A. P.; JONES, E. T. Integrating traditional and local ecological knowledge into forest biodiversity conservation in the Pacific Northwest. Forest Ecology and Management, v. 246, p. 14-28, 2007.

CHIZZOTTI, A. Pesquisa qualitativa em ciências humanas e sociais. 4. ed. Petrópolis, RJ: Vozes, 2011, 144 p.

COOMES, O. T.; GRIMARD, F.; BURT, G. J. Tropical forests and shifting cultivation: secondary forest fallow dynamics among traditional farmers of the Peruvian Amazon. Ecological Economics, v. 32, p. 109-124, 2000.

COSTA, J. R.; MITJA, D. Uso dos recursos vegetais por agricultores familiares de Manacapuru (AM). Acta Amazonica, v. 40, n. 1, p. 4-58, 2010.

CUNHA, M. C.; ALMEIDA, M. W. B. Indigenous people, traditional people, and conservation in the Amazon. Daedalus, v. 29, n. 2, p. 315-338, (Brazil: The Burden of the Past; The Promix of the Future), Spring, 2000.

DIEGUES, A.C. O mito moderno da natureza intocada. 6 ed. São Paulo: Hucitec, 2008, 198 p.

DIEGUES, A. C.; ARRUDA, R. S. V. Saberes tradicionais e biodiversidade no Brasil. Brasília: Ministério do Meio Ambiente: São Paulo: Universidade de São Paulo-USP, 2001, 176 p. 
DINIZ, F. P. S. Território e Desenvolvimento Sustentável no assentamento agro-extrativista Nova Esperança-llha de João Pilatos, Ananindeua/PA. In: III Jornada de Pós-Graduação da Fibra, Faculdade Integrada Brasil Amazônia, 2010. Anais da III Jornada de Pós-Graduação da FIBRA, Belém, 2010.

DINIZ, F. P. S. et al. Saberes e práticas educativas ambientais como princípios basilares da construção de territórios da sustentabilidade no assentamento Agroextrativista Igarapé Grande, ilha João Pilatos/Ananindeua-PA. Revista Vitas - Visões Transdisciplinares sobre Ambiente e Sociedade, n. 3, 2012.

ELISABETSKY, E. Etnofarmacologia. Ciência e Cultura, v. 55, n. 3, p. 3536, 2003.

EMPERAIRE, L.; ELOY, L. A cidade, um foco de diversidade agrícola no Rio Negro (Amazonas, Brasil)? Boletim do Museu Paraense Emílio Goeldi, Ciências Humanas, v. 3, n. 2, p. 195-211, 2008.

FEARNSIDE, P. M. Agricultura na Amazônia. Tipos de Agricultura: padrão e tendências. Cadernos NAEA, v. 10, p. 197-252, 1989.

FEARNSIDE, P. M. Desmatamento na Amazônia brasileira: história, índices e consequências. Megadiversidade, v. 1, n. 1, p. 113-123, 2005.

FEARNSIDE, P. M. Amazon forest maintenance as a source of environmental services. Annals of the Brazilian Academy of Sciences, v. 80 , n. 1, p. $101-114,2008$.

FERNANDES, E. C. M.; NAIR, P. K. R. An evaluation of the structure and function of tropical homegardens. Agricultural Systems, v. 21, p. 279$310,1986$.

FERRARO, A. R. Alfabetização rural no Brasil na perspectiva das relações campo-cidade e gênero. Educação e Realidade, Porto Alegre, v. 37, n. 3, p. 943-967, 2012. 
FERREIRA, L. V. et al. O efeito da fragmentação e isolamento florestal das áreas verdes da região metropolitana de Belém. Pesquisas Botanica, n. 63, p.357-367, 2012.

GADGIL, M.; BERKES, F.; FOLKE, C. Indigenous knowledge for biodiversity conservation. Ambio, v. 22, n. 2-3, p.151-156, 1993.

GALUZZI, G.; EYZAGUIRRE, P.; NEGRI, V. Home gardens: neglected hotspots of agro-biodiversity and cultural diversity. Biodiversity and Conservation, v. 19, p. 3635-3654, 2010.

GAZONI, J. L.; MOTA, J. A. Fatores político-econômicos do desmatamento na Amazônia Oriental. Sustentabilidade em debate, v. 1, n. 1 , p. $25-42,2010$.

GÓMEZ-BAGGETHUN, E. et al. Traditional ecological knowledge trends in the transition to a market economy: empirical study in the Doñana natural areas. Conservation Biology, v. 24, n. 3, p. 721-729, 2010.

HANAZAKI, N. et al. Conservação biológica e valorização sócio-cultural: explorando conexões entre a biodiversidade e a sociodiversidade. In: ALVES, Angelo G. C.; SOUTO, F. J. B.; PERONI, N. Etnoecologia em perspectiva: natureza, cultura e conservação. Recife: NUPEEA, 2010, p. 91-102.

HECKENBERG, M. J. et al. Amazonia 1492: pristine forest or cultural parkland. Science, v. 301, p. 1710-1714, 2003.

HECKENBERG, M. J. et al. The legacy of cultural landscapes in the Brazilian Amazon: implications for biodiversity. Philosophical Transactions of Royal Society, v. 362, p. 197-208, 2007.

HOLE, D. G. et al. Does organic farming benefit biodiversity? Biological Conservation, v. 122, p. 113-130, 2005.

HOMMA, A. K. O. Amazônia: como aproveitar os benefícios da destruição. Estudos Avançados, v. 19, n. 54, p. 115-135, 2005. 
HURTIENNE, T. Agricultura familiar e desenvolvimento rural sustentável na Amazônia. Novos Cadernos NAEA, v. 8, n. 1, p. 19-71, 2005.

INCRA - Instituto Nacional de Colonização e Reforma Agrária. Projetos de Reforma Agrária conforme fases de implementação. Incra, 2011.

JACKSON, L. E.; PASCUAL, U.; HODGKIN, T. Utilizing and conserving agrobiodiversity in agricultural landscapes. Agriculture Ecosystems and Environment, v. 121, p. 196-210, 2007.

KITAMURA, P. C. Agricultura migratória na Amazônia: um sistema de produção vivável. EMBRAPA-CPATU, Documentos, v.12, p. 5-22, 1982.

LEAL, E. C.; VIEIRA, I. C. G.; KATO, M. S. A. Banco de sementes em sistemas de produção de agricultura com queima e sem queima no município de Marapanim. Boletim do Museu Paraense Emílio Goeldi, Ciências Naturais, v. 1, n. 1, p. 19-29, 2006.

LEÃO, N.; ALENCAR, C.; VERÍSSIMO, A. Belém Sustentável 2007. Belém: Instituto do Homem e do Meio Ambiente da Amazônia, 2008, 140 p.

LEITE, D. L. et al. Agrobiodiversidade como base para sistemas agrícolas sustentáveis para a agricultura familiar. Documentos, v. 354, Pelotas: Embrapa Clima Temperado, 2012.

LÉVI-STRAUSS, C. O pensamento selvagem (Tradução: Tânia Pellegrini). Campinas, SP: Papirus, 1989, 320 p.

LIMA, D.; POZZOBON, J. Amazônia Socioambiental: sustentabilidade ecológica e diversidade social. Estudos Avançados, v. 19, n. 54, p. 45$54,2005$.

LIMA, D.; STEWARD, A.; RICHERS, B. T. Trocas, experimentações e preferências: um estudo sobre a dinâmica da diversidade da mandioca no médio Solimões, Amazonas. Boletim do Museu Paraense Emílio Goeldi, Ciências Humanas, Belém, v. 7, n. 2, p. 371-396, 2012. 
LIMA, P. G. C. et al. Agrobiodiversidade e etnoconhecimento na Gleba Nova Olinda I, Pará: interações sociais e compartilhamento de germoplasma da mandioca (Manihot esculenta Crantz, Euphorbiaceae). Boletim do Museu Paraense Emílio Goeldi, Ciências Humanas, Belém, v. 8, n. 2, p. 419-433, 2013.

LUIZÃO, F. J. et al. The maintenance of soil fertility in Amazonian managed systems. In: KELLER, M.; BUSTAMANTE, M.; GASH, J.; DIAS, S. P. (Eds.). Amazonia and global change. Geophysical Monograph Series, v. 186, Washignton D. C, USA: American Geophysical Union (AGU), 2009, p. 311-336.

MACHADO, D. Catadoras de caranguejo e saberes tradicionais na conservação de manguezais da Amazônia brasileira. Estudos Feministas, v. 15 , n. 2 , p. $485-490,2007$.

MARTINS, P. S. Dinâmica evolutiva em roça de caboclos amazônicos. Estudos Avançados, v. 19, n. 53, p. 209-220, 2005.

MARTINS, W. M. O. et al. Agrobiodiversidade nos quintais e roçados ribeirinhos na comunidade Boca de Môa - Acre. Biotemas, v. 25, n. 3, p. $111-120,2012$.

MARTINELLI, L. A.; FILOSO, S. Balance between food production, biodiversity ande cosystem services in Brazil: a chanllenge and an opportunity. Biota Neotropica, v. 9, n. 4, p. 21-25, 2009.

MAZOYER, M.; ROUDART, L. História das agriculturas no mundo: do neolítico à crise contemporânea. Tradução: Cláudia F. Falluh Balduino Ferreira. São Paulo: Editora Unesp; Brasília: NEAD, 2010, 568 p.

MCNEELY, J. A.; SCHROTH, G. Agroforestry and biodiversity conservation: traditional practices, present dynamics, and lessons for the future. Biodiversity and Conservation, v. 15, p. 549-554, 2006.

MERCADANTE, M. Da agricultura Neolítica aos organismos transgênicos. In: BENSUSAN, N. (Org.). Seria melhor ladrilhar? Biodiversidade: como, 
para que e por quê. 2 ed. São Paulo: Peirópolis; Brasília, DF: Editora da Universidade de Brasília, 2008, p. 293-302.

MILLENIUM ECOSYSTEM ASSESSMENT - MEA. Ecosystems and human well-being: biodiversity synthesis. World Resources Institute: Washington, DC, 2005, 86 p.

MITTERMEIER, R. A. et al. Wilderness and Biodiversity Conservation. Proceedings of the National Academy of Sciences, v. 100, n.18, p. 10309-10313, 2003.

MORAES, R. Análise de Conteúdo. Revista Educação. v. 37, p. 7-32, 1999.

MORAN, E. F. A ecologia humana das populações da Amazônia. Petrópolis, RJ: Vozes, 1990, 367 p.

MORAN, E. F. et al. Effects of soil fertility and land-use on forest succession in Amazônia. Forest Ecology and Management, v. 139, p. 93108, 2000.

NAIR, P. K. R. An introduction to agroforestry. Dordrecht: Kluwer Academic Publishers/ICRAF, 1993, 499p.

NEPSTAD, D. C. et al. Interactions among Amazon land use, forests and climate: prospects for a near-term forest tipping point. Philosophical Transactions of Royal Society, v. 363, 1737-1746, 2008.

NODA, S. N. et al. Contexto Sócioeconômico da Agricultura Familiar nas Várzeas do Amazonas. In: NODA, Sandra do Nascimento (Org.). Agricultura Familiar na Amazônia das Águas. Manaus: Editora da Universidade Federal do Amazonas, 2007, p. 23-65.

NODA, S. N. et al. Paisagens e etnoconhecimento na agricultura Ticuna e Cocama no alto rio Solimões, Amazonas. Boletim do Museu Paraense Emílio Goeldi, Ciências Humanas, Belém, v. 7, n. 2, p. 397-416, 2012. 
OLIVEIRA, A. M. Saberes camponeses e práticas pedagógicas no campo. Mercator, v. 7, n. 13, p. 48-58, 2008.

PASCUAL, U.; PERRINGS, C. Developing incentives and economics mechanisms for in situ biodiversity conservation in agricultural landscapes. Agriculture, Ecosystems and Environment, v. 121, p. 256268, 2007.

PATERNIANI, E. Agricultura sustentável nos trópicos. Estudos Avançados, v. 15, n. 43, p. 303-326, 2001.

PEDROSO JUNIOR, N. N.; MURRIETA, R. S. S.; ADAMS, C. A agricultura de corte e queima: um sistema em transformação. Boletim do Museu Paraense Emílio Goeldi, Ciências Humanas, Belém, v. 3, n. 2, p. 153174, 2008.

PEREIRA, B. E.; DIEGUES, A. C. Conhecimento de populações tradicionais como possibilidade de conservação da natureza: uma reflexão sobre a perspectiva da etnoconservação. Desenvolvimento e Meio Ambiente, v. 2, n. 22, p. 37-50, 2010.

PEREIRA, C. A.; VIEIRA, I. C. G. A importância das florestas secundárias e os impactos de sua substituição por plantios mecanizados de grãos na Amazônia. Interciência, v. 26, n. 8, p. 337-341, 2001.

PEREIRA, K. J. C. Agricultores e (pescadores) da Amazônia Central Brasileira: racionalidades e trajetória recente dos sistemas agrícolas em duas unidades de conservação do médio Solimões, Amazonas. Revista Brasileira de Agroecologia, v. 6, n. 3, p. 115-137, 2011.

PEREIRA, K. J. C. et al. Saber tradicional, agricultura e transformação da paisagem na Reserva de Desenvolvimento Sustentável Amanã, Amazonas. Uakari, v. 2, n. 1, p. 9-26, 2006.

PIMENTEL, A. M. P. Olericultura no trópico úmido: hortaliças da Amazônia. São Paulo: Editora Agronômica Ceres, 1985, 322 p. 
POSEY, D. A. Manejo da floresta secundária, capoeiras, campos e cerrados (Kayapó). In: RIBEIRO, D. (Ed.). Suma Etnoecológica Brasileira. Edição atualizada do Handbook of South American Indians. p. 173-185, Petrópolis, RJ: FINEP, 1986, p. 173-185.

POTTER-BOLLAND, L. et al. Community managed forests and forest protected areas: an assessment of the conservation effectiveness across the tropics. Forest Ecology and Management, v. 268, p. 6-17, 2012.

PRIMACK, R.; RODRIGUES, E. Biologia da Conservação. Londrina: Planta, 2001.

RAMSTAD, K. M. et al. Species and Cultural Conservation in New Zealand: Maori Traditional Ecological Knowledge of Tuatara. Conservation Biology, v. 21, n. 2, p. 455-464, 2007.

REYES-GARCIA, V. Conocimiento ecológico tradicional para La conservacion: dyanamicas y conflitos. Papeles de relaciones ecosociales y cambio global, n. 107, p. 57-67, 2009.

RICHERS, B. T. T. Agricultura migratória em ambientes de várzea na Amazônia Central: ameaça ou sistema integrado? Uakari, v. 6, n. 1, p. 27-37, 2010.

RIVERO, S. et al. Pecuária e desmatamento: uma análise das principais causas diretas do desmatamento na Amazônia. Novas Economias, Belo Horizonte, v. 9, n. 1, p. 41-66, 2009.

ROBERT, P. et al. A beleza das roças Mebêngôkre-Kayapó em tempos de globalização. Boletim do Museu Paraense Emílio Goeldi, Ciências Humanas, v. 7, n. 2, p. 339-369, 2012.

RODRIGUES, M. A. C. M.; MIRANDA, I. S.; KATO, M. S. A. Estruturas de florestas secundárias após dois diferentes sistemas agrícolas no nordeste do Estado do Pará, Amazônia Oriental. Acta Amazonica, v. 37, n. 4, p. 591-598, 2007. 
RYLANDS, A. B. et al. Amazonia. In: MITTERMEIER, R. A.; MITTERMEIER C. G.; GIL, P. R.; PILGRIM, J., FONSECA, G. A. B.; BROOKS, T.; KONSTANT W. R. (Ed.). Wilderness: Earth's last wild places. CEMEX, Agrupaci' on Serra Madre, S. C., Mexico, 2002.

SANTOS, R. S.; COELHO-FERREIRA, M. Artefatos de miriti (Mauritia Flexuosa L. f.) em Abaetetuba, Pará: da produção à comercialização. Boletim do Museu Paraense Emílio Goeldi, Ciências Humanas, Belém, v. 6, n. 3, p. 559-571, 2011.

SEOANE, C. E. et al. Atividades e práticas em coletivos de trabalho mutirões - em agroflorestas agroecológicas do litoral do Paraná, Brasil. Cadernos de Agroecologia, v. 8, n. 2, p. 1547-1551, 2013.

SHEN, X. et al. Does science replace traditions? Correlates between traditional Tibetan culture and local bird diversity and Southwest China. Biological Conservation, 145, p. 160-170, 2012.

SILVA, F. P.; FRAXE, T. J. Saberes de populações tradicionais: etnociência em processos de bioconservação. Contribuciones a las Ciencias Sociales, Agosto 2013.2 Disponível em: $<$ http://www.eumed.net/rev/cccss/25/biodiversidade.html $>$.

SILVA JUNIOR, R. D.; BIASE, L. Na encruzilhada dos saberes e práticas: inserções antropológicas sobre estranhamento e alteridade no interior da Agroecologia. Revista Brasileira de Agroecologia, v. 7, n. 2, p. 3-18, 2012.

SIMONIAN, L. T. L. Pescadoras de camarão: gênero, mobilização e sustentabilidade na ilha de Trambioca, Barcarena, Pará. Boletim Museu Paraense Emílio Goeldi, Ciências Humanas, Belém, v. 1, n. 2, p. 35-52, 2006.

SOUSA, M. J. S. Etnografia da produção de artefatos e artesanatos em comunidades da Reserva de Desenvolvimento Sustentável Amanã Médio Solimões. Uakari, v. 5, n. 1, p. 21-37, 2009. 
SOUSA, R. E. M.; SILVA, M. G, S. N. Mulher: a quebra do paradigma da função reprodutiva. Revista Geografares, n. 10, p. 203-224, 2012.

STEFANELO, F. V. Análise do instituto da Reserva Legal e do atual cenário de degradação. Prisma Jurídico, v. 8, n. 2, p. 523-542, 2009.

TOLEDO, V. M; BARRERA-BASSOLS, N. La Memória Biocultural: la importancia ecológica de las sabidurías tradicionales. Barcelona: Icaria Editorial, Perspectivas Agroecológicas, 2008, 230 p.

TOLEDO, V. M; BARRERA-BASSOLS, N. A Etnoecologia: uma ciência pósnormal que estuda as sabedorias tradicionais. Desenvolvimento e Meio Ambiente, n. 20, p. 31-45, 2009.

TOSETTO, E. M.; CARDOSO, I. M.; FURTADO, S. D. C. A importância dos animais nas propriedades familiares rurais agroecológicas. Revista Brasileira de Agroecologia, v. 8, n. 3, p. 12-25, 2013.

VEIGA, D. V. et al. Alternativas de recuperação da fertilidade do solo em sistema agrícola de subsistência no nordeste paraense. Revista Brasileira de Agroecologia, v. 7, n. 1, p. 111-120, 2012.

VIEIRA, I. C. G. et al. Deforestation and threats to the biodiversity of Amazonia. Brazilian Journal of Biology, v. 68, n. 4 (suplemento), p. 949956, 2008.

VIEIRA, T. A.; ROSA, L. S.; SANTOS, M. M. L. S. Agrobiodiversidade de quintais agroflorestais no município de Bonito, Estado do Pará. Revista de Ciências Agrárias, v. 55, n. 3, p. 159-166, 2012.

VIEIRA, T. A. et al. Sistemas agroflorestais em áreas de agricultores familiares em Igarapé-Açu, Pará: caracterização, florística, implantação e manejo. Acta Amazonica, v. 37, n. 4, p. 549-558, 2007.

WILLERDING, A. L.; OLIVEIRA, L. A. Diagnóstico de um projeto de enriquecimento florestal na comunidade do Brasileirinho, Manaus, Amazonas. Acta Amazonica, v. 35, n. 4, p. 421-426, 2005. 
Submetido em

Aprovado em

Sobre os autores

Neriane Nascimento da Hora

Mestre em Ciências Ambientais - Universidade do Estado do Pará. Doutorado em andamento em Sociedade, Natureza e Desenvolvimento - Universidade Federal do Oeste do Pará.

E-mail: neri.dahora@gmail.com

\section{Hélio Raymundo Ferreira Filho}

Dr. Em Ciências da Gestão. Professor Adjunto - Universidade do Estado do Pará.

Endereço: Travessa Doutor Enéas Pinheiro, 2626, Marco. 66095015 - Belém - PA Brasil.

E-mail: hlio.ferreira@gmail.com

\section{Ana Cláudia Caldeira Tavares Martins}

Dra. em Botânica. Professora Assistente - Universidade do Estado do Pará.

E-mail: tavaresmartins7@gmail.com

\section{Maria de Jesus da Conceição Ferreira Fonseca (In memorian)}

Dra. em Ciências Biológicas. 